\section{OC-054 OBJECTIVE ASSESSMENT OF AEROPHAGIA DURING MEALS IN NORMAL CONTROLS AND PATIENTS WITH POST-PRANDIAL BLOATING AND BELCHING}

doi:10.1136/gut.2011.239301.54

P Woodland, ${ }^{1,}$ R S Gill, ${ }^{1}$ J Jafari, ${ }^{1}$ I Bravi, ${ }^{1}$ R Shimono, ${ }^{1}$ A Fikree, ${ }^{1}$ J Hayat, ${ }^{1}$ E Yazaki, ${ }^{1}$ A J Bredenoord, ${ }^{2}$ D Sifrim ${ }^{1}{ }^{1}$ Barts and The London School of Medicine and Dentistry, Queen Mary University of London, London, UK; ${ }^{2}$ Dept of Gastroenterology, Academic Medical Centre, Amsterdam, Netherlands

Introduction Many patients attending GI physiology units for assessment of dysphagia and GORD also complain of postprandial bloating and/or belching. Excessive fasting aerophagia has been recently described in patients with severe continuous bloating and belching. Exaggerated air swallowing during meals might be more relevant for postprandial symptoms but, thus far, objective assessment of prandial aerophagia and normal values are lacking. Oesophageal impedance can detect air swallowing. We aimed to quantify aerophagia during meals in asymptomatic subjects and patients with postprandial bloating and belching.

Methods We assessed aerophagia during meals using ambulatory impedance-pH monitoring in 39 healthy, asymptomatic controls (from the US-Belgian MII-pH Normal value study, Shay et al. 2004; mean age in original study 39, range 22-62) to establish normal $95 \%$ confidence intervals. We identified 38 patients (mean age 43, range 17-74) with postprandial bloating and/or belching who attended the GI physiology unit for assessment of dysphagia or GORD as primary symptoms. Mealtime air swallows were visually identified when swallows were associated with antegrade flow and fast impedance increase (at least $3000 \Omega$ from baseline) in the most distal recording segment. A score of air swallows/10 min mealtime was calculated for each subject. In patients with mealtime exaggerated air swallowing (above 95th percentile of normal values) we examined for evidence of concomitant fasting aerophagia.

Results The $95 \%$ percentile range of mealtime aerophagia in normal subjects was 6.8 to 9.4 episodes $/ 10$ min, mean 8.1. Patients had significantly higher mealtime air swallowing rates than controls (mean 11.8 episodes/10 min, SEM 1.0, $\mathrm{p}=0.003$ ). There was no significant difference between predominant bloating and belching subgroups. Only 4 of

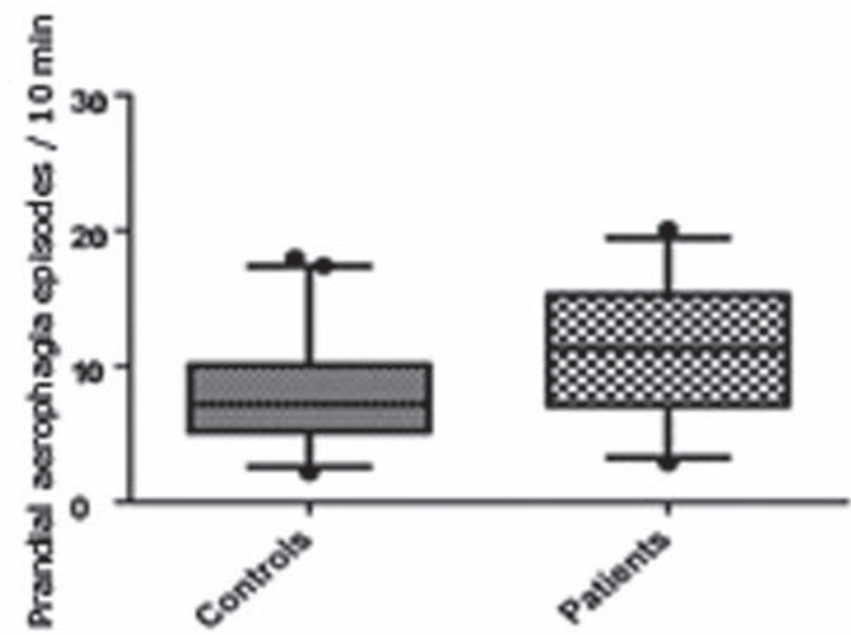

Figure 1 OC-054 Prandial aerophagia in normal controls and patients with belching and bloating
23 patients with exaggerated mealtime air swallowing had concomitant fasting aerophagia.

Conclusion We established normal values of mealtime air swallowing using oesophageal impedance. Patients with postprandial bloating and/or belching exhibit increased aerophagia during meals. Most of these patients do not have fasting aerophagia. Exaggerated air swallowing during meals can now be objectively detected and biofeedback techniques can be attempted to modify such behaviour as a potential therapeutic strategy for these patients with functional GI symptoms.

Competing interests P. Woodland: None Declared, R. Gill: None Declared, J. Jafari: None Declared, I. Bravi: None Declared, R. Shimono: None Declared, A. Fikree: None Declared, J. Hayat: None Declared, E. Yazaki: None Declared, A. Bredenoord: None Declared, D. Sifrim Grant / Research Support from: Sandhill Scientific US.

Keywords aerophagia, belching, bloating, dyspepsia, impedance.

\section{REFERENCES}

1. Shay S, Tutuian R, Sifrim D, Vela M, Wise J, Balaji N, et al. Twenty-four hour ambulatory simultaneous impedance and $\mathrm{pH}$ monitoring: a multicenter report of normal values from 60 healthy volunteers. Am J Gastroenterol 2004;99(6):1037-43. 